\title{
Editorial (For Volume 5 \# 1)
}

\author{
Niles Eldredge
}

Published online: 28 March 2012

(C) Springer Science+Business Media, LLC 2012

Natural history museums ranked right up there with art museums, opera houses, and symphony halls when it came to raising the cultural profiles of America's cities in the nineteenth century. And, despite the modern advent of highquality films, TV shows and now, of course, the Internet (where nature is often displayed in its full, and even gory, glory), natural history museums remain near the top of the list of destinations for tourists and locals alike. In a large city like New York, for many younger people, natural history museums (along with zoos, of course) remain the most convenient - and often, the only - way of getting close to the natural world.

But, with rare exceptions ever since Darwin published his On the Origin of Species in 1859, evolution has tended to play only cameo roles in the exhibition programming at natural history museums. The fiftieth, one hundredth, and, most recently, one hundred and fiftieth anniversaries of the Origin (coincidentally the hundredth, hundred and fiftieth, and two hundredth anniversaries of Darwin's birth in 1809) - have always triggered some exhibitions marking the occasion. For example, I curated the exhibition Darwin at the American Museum of Natural History - which opened in late 2005 as an early "birthday present" to the man who founded the modern science of evolutionary biology. I am happy to report that Darwin is still on display as it travels around the world.
But times have been changing, at long last. And though there is still a reluctance in many places to mount exhibitions explicitly devoted to evolutionary themes - a reluctance engendered by the fear of "controversy"-many exhibition and educational departments at natural history museums, whether in the Unites States or elsewhere, have stepped up the pace of presenting the modern understanding of evolution to the public.

It is a challenge to present evolutionary concepts such as natural selection, speciation, or even simply "descent with modification" in an exhibition context. The papers in this special issue on Museums and Evolution, ably assembled by our guest editor Dr. Monique Scott, offer a fascinating survey of recent experiences of museum educators and scientists as they begin to grapple with the challenges of effective communication of theoretical evolutionary concepts along with the more usual evidence afforded by modern and fossil bones and shells, and now along with molecules, that provide the crucial, convincing evidence that life has had a long, rich evolutionary history on this earth.

Hats off to natural history museums - and their willingness to embrace evolution in their educational programming and exhibition halls!

N. Eldredge $(\bowtie)$

Division of Paleontology,

The American Museum of Natural History,

New York, NY 10024, USA

e-mail: epunkeek@amnh.org 